\title{
Los caminos de la historia del arte. Una reflexión breve, pensando en los tiempos que corren, sobre los déficits y obstáculos de esta disciplina
}

\author{
Vicente Luis Galbis y Giner | Universitat de València \\ URL de la contribución <www.iaph.es/revistaph/index.php/revistaph/article/view/3439>
}

De acuerdo con los tiempos que corren, la historia del arte no puede quedarse en el punto académico en que se encuentra. Es posible abrir nuevos caminos que ofrezcan una salida profesional más nítida puesto que ha aumentado la competencia, han surgido nuevos agentes formadores y la presencia y la difusión del conocimiento desborda ya nuestros límites. Son necesarias nuevas vías de trabajo que pasan por acercar las diferencias entre las demandas reales y lo que la universidad y los alumnos creen necesario, por rediseñar los principios educativos que mueven la docencia universitaria, por platearse seriamente el tema de la formación continua, por apostar por una parte del aprendizaje en línea, por enseñar a hacer disfrutar a nuestros alumnos del descubrimiento del placer de aprender.

Supongo que resulta evidente que la historia del arte y los historiadores del arte ni construyen, ni esculpen, ni pintan, así como que, viendo y sintiendo los tiempos que corren, no es posible estar hablando simplemente de museos, artistas, restauración y técnicas decorativas, de estudiosos de las obras de arte y su evolución a lo largo de la Historia. Pero entonces creo que podemos y debemos preguntarnos: ¿para qué sirve la historia del arte?, ¿cuáles son los caminos de esta disciplina?

Según el Libro Blanco del Programa de Convergencia Europea de la ANECA (aprobado por los 29 directores de departamentos de historia del arte de las universidades españolas el 12 de diciembre de 2007), esta disciplina sirve para dos cosas. En primer lugar para proporcionar conocimientos (racionales y críticos, eso sí). $\mathrm{Y}$, en segundo lugar, para preparar al alumno ("capacitarlo", señalaron los directores de departamentos) para la práctica profesional según la demanda social (atendiendo especialmente al mercado laboral). Algo, esto último especialmente pedido desde el Espacio Europeo de Educación Superior (EEES), junto a la empleabilidad de los universitarios una vez concluidos sus estudios.

Si ésta parece no ser una carrera con una salida profesional nítida, ni de evidente y clara demanda social, cabrá entonces empezar a plantearse como necesario rediseñar el futuro de la misma (su currículo), indagando caminos que la hagan necesaria (dando forma a las necesidades y deseos de los posibles clientes).

Hasta ahora al hablar de la orientación profesional de los historiadores del arte pensábamos en la docencia, la investigación y la generación de nuevo conocimiento; en los museos, exposiciones y galerías; en la gestión, conservación y restauración del patrimonio; en la crítica de arte; los informes técnicos patrimoniales; en ejercer como guía turístico; actuar como documentalista de información artística y poco más. Pero, como decía antes, a la vista de lo que estamos viendo y sintiendo, es necesario buscar nuevos caminos. Y es que en la actual sociedad del conocimiento las universidades debemos plantearnos seriamente que nos desenvolvemos en un medio donde ha aumentado la competencia, donde han surgido nuevos agentes formadores y donde la presencia y la difusión de dicho conocimiento desborda nuestros límites.

La cruda realidad es que existe una diferencia entre lo que los estudiantes piensan que les van a pedir las empresas y las demandas reales de éstas. Mientras las empresas consideran vitales aspectos tales como la motivación, la resolución de problemas o la gestión del tiempo, los estudiantes ven dichas habilidades como una cosa secundaria, priorizando factores como la formación en idiomas (no tan importante para muchas entidades). El Grupo Adecco, uno de los principales proveedores de 
a debate Historiadores del arte ¿para qué? Una titulación en busca de una profesión | coordina José Castillo Ruiz

recursos humanos a nivel mundial, ha señalado cómo la universidad tiene carencias de formación en habilidades transversales. Cómo la transición entre la formación y el empleo se encuentra con piedras en el camino, ya que existe un desajuste entre lo que se aprende y lo que se exige en un empleo, así como una diferencia entre lo que la universidad piensa que le piden las empresas y lo que éstas demandan realmente. Por ambas causas resulta necesario que estudiantes, empresas y centros educativos trabajen en la misma dirección. Es preciso que la universidad tenga presente el contexto social, económico y cultural, para poder así anticiparse a las necesidades de la sociedad, cambiantes y diversas. $Y$ es que la universidad no puede aislarse del medio en el que se desarrolla, cayendo en el corporativismo y el alejamiento por defender su autonomía, sino que necesita de un vínculo dinámico con su contexto, estar atenta a las distintas demandas y necesidades (individuales, del sector público, de organizaciones sociales, del sector privado, etc.). Orientación en la que "...no faltan las exhortaciones a que cada universidad se singularice de las demás, desarrolle un 'perfil' propio y haga uso de su autonomía para diseñar estrategias y actividades ajustadas a sus capacidades específicas y/o a las necesidades de su entorno" (HAUG, 2013).

Antes de seguir desgranando ideas, sería necesario tener claro (pues que éstas fluyan creo que depende de ello) que existen cuatro principios educativos que no deberíamos perder de vista:

- Aprendizaje eficaz: las enseñanzas, para que el aprendizaje sea eficaz, deben ser útiles, servir para poner al discente en el camino de la vida (la mayoría de las personas no sólo no sabe cómo aprender, sino que ni siquiera es consciente de que ello resulte necesario), convirtiéndolo en un participante realmente competente. De manera que sepa reconocer y asumir una determinada identidad de hacer y estar en el mundo: uso del lenguaje, de herramientas de trabajo concretas, etc.

- Aprendizaje integrado: no se trata de que ser práctico esté de moda, igual que antes lo fue ser teórico, sino de generar un aprendizaje integrado como proceso de planificación, análisis y táctica que dé como resultado profesionales capaces de resolver problemas a través de la investigación y actualización constante, y no de la simple intuición y la experiencia práctica sin criterio (GUARRERA, 2001: 37-38). Así, el conocimiento adquirido una vez procesado no se olvida, ya que la experiencia no proviene de los objetos sino de la acción del sujeto sobre los mismos.

- Apropiación y extensión productivas del aprendizaje: hablamos aquí de adecuar la transmisión de la enseñanza a los aspectos culturales, personales y tecnológicos de quien la recibe, al tiempo que de utilizar los conocimientos previos, lo que ya se sabe y se ha experimentado, para que lo transmitido sea apropiado por el discente más fácilmente. Si los alumnos ya saben ejecutar roles y tareas discursivas relacionados con el objeto de aprendizaje, esto puede utilizarse para facilitar dicho aprendizaje.

- Aprendizaje crítico: imprescindible en la sociedad de la información, nos ofrece la posibilidad de ver las limitaciones de las opciones generando una visión crítica y creativa sobre las mismas (evitando caer, eso sí, en el escepticismo o la criticidad compulsiva). Nos obliga a revisar a cada instante el alcance de las tareas escogidas y con las cuales se progresa, con el fin de enriquecer nuestro trabajo. Esto resulta necesario para evitar falsos aprendizajes y llegar a mejores conclusiones, evaluar la información con mayor acierto, abrir nuestra razón a nuevas consideraciones, abordar la complejidad, "dar en el clavo". Y es que es preciso dotar a los universitarios de una serie de destrezas cognitivas que les permitan interrogarse sobre las cosas y desenvolverse con soltura, rigor y seriedad tanto en el mundo académico como en cualquier otro ámbito de la vida.

A la vista de estos cuatro principios cabría preguntarse si honradamente se llevan o no adelante. Ya que si se sucumbe a la docencia tradicional es difícil conseguirlo. Un docente actual, ajustado a los planes del EEES, ya no puede dedicarse simplemente a buscar, analizar y 
a debate Historiadores del arte ¿para qué? Una titulación en busca de una profesión | coordina José Castillo Ruiz

ofrecer información a su alumnado, a ser un poseedor y dictador del saber (en cuanto que dicta apuntes) sino que debe constituirse en un facilitador del acceso y la gestión de la información, en un acompañante del desarrollo y el aprendizaje de los estudiantes, de forma que éstos puedan conseguir objetivos de aprendizaje concretos, tales como gestionar la información que necesitan, tomar decisiones adecuadas al respecto, resolver problemas que vayan surgiendo mediante la localización de la información necesaria para solucionarlos, etc. La avalancha de información y documentación es hoy ingente, y aprender todo lo necesario para ser un buen historiador del arte resulta imposible. Además, esta disciplina precisa de enfoques sobre conocimientos diferentes. No obstante, es evidente que no todas las asignaturas pueden soportar los rumbos de enseñanza y aprendizaje que una parte de la economía y la sociedad demandan.

Brevemente expongo a continuación tres de los posibles nuevos caminos:

- El primero supondría plantearse seriamente el tema de la formación continua ligada al aprendizaje en línea. Dicho aprendizaje puede ofrecer un triple beneficio. Por una parte el acceso a la formación de dos tipos de personas: aquellos que no pueden pagar un coste universitario que no sea económicamente rentable, acorde a sus posibilidades; y aquellos que quieren mejorar sus competencias y su competitividad (e incluso aumentar sus ingresos) o simplemente mejorar su cultura, y que por cuestiones de trabajo o familiares no tienen el tiempo de quien no tiene estas "cargas" y precisan de la flexibilidad que este tipo de aprendizaje puede ofrecer. Por otra parte, un segundo beneficio sería la oportunidad que darían los ingresos generados por estos individuos de contratar más profesorado o simplemente mejorar los servicios de los departamentos de historia del arte. Por último, el tercer beneficio lo constituiría la posibilidad de ajustar la enseñanza a la nueva economía, basada en la información, en la industria del conocimiento. De forma que una vez se accediese al mercado laboral los alumnos estarían preparados para la realidad que supone el que no basta con estar muy forma- dos, sino que es imprescindible continuar aprendiendo. Hacer realidad todo lo cual implica más bien inquietudes y búsqueda de nuevos caminos, que preocupación por artefactos y entornos tecnológicos. En España tenemos un muy buen ejemplo de ello en la Universitat Oberta de Catalunya.

- Otro de los caminos, obvio en el espacio cada día más amplio de entornos virtuales en que nos movemos, sería el de realizar una parte de la enseñanza-aprendizaje en línea. Consiguiendo con ello un doble beneficio. De un lado, una vez encauzado correctamente el tema del elearning (BAUTISTA; BORGES; FORÉS, 2008), supondría la posibilidad de ampliación del tiempo a dedicar a la investigación por parte de los docentes (aunque el principio es dificultoso y engorroso en su implementación, los entornos virtuales de aprendizaje facilitan horarios, sistemas de trabajo, planificación, etc.). Y, de otro, la aproximación al futuro del trabajo por parte de los discentes: la navegación en el conocimiento, el trabajo en equipo, la capacidad de aprender (formación continua) de forma independiente, la capacidad de adaptarse a las circunstancias cambiantes.

- Por último, quisiera dejar sobre la mesa un último camino, en un plano más inmaterial, pero pienso que no de menor importancia. Enseñar a hacer disfrutar a nuestros alumnos del tiempo vivido individual y colectivo (como dirían los griegos, del kairós). Con ello, con el descubrimiento del placer de aprender (ASSMANN, 2002; BATESON, 2013), con un buen uso del tiempo dedicado a ello, sabiendo adónde queremos llegar y haciendo partícipes de esto a nuestros estudiantes, cabe lograr que: la educación se preocupe de generar experiencias de aprendizaje, de creatividad para construir conocimientos, y de habilidad para saber acceder a fuentes de información sobre los más diversos asuntos. Mediante la dosificación de su instrucción, entendimiento y manejo de reglas, y el reconocimiento de saberes ya acumulados por la humanidad. Es preciso sustituir la pedagogía de las certezas y de los saberes prefijados por una pedagogía de la pregunta y el acceso a las informaciones. Teniendo presente que el nuevo encanto y el nuevo 
a debate Historiadores del arte ¿para qué? Una titulación en busca de una profesión | coordina José Castillo Ruiz

placer de la educación requiere la unión entre sensibilidad social y eficiencia pedagógica, así como la consecución de ambientes que propicien experiencias de conocimiento (mediante la suma del talento, los conocimientos, las habilidades y las experiencias).

Finalmente, quiero señalar que en esta búsqueda de los caminos de la historia del arte no pueden estar únicamente implicados los profesores sino también los autores y diseñadores de materiales didácticos, la universidad y su personal de gestión académica (que deben dirigir y gestionar con eficacia y eficiencia la toma de decisiones, un buen ejemplo de interés por conseguir dicho objetivo es el del máster en política y gestión universitaria de la Universitat de Barcelona), y las instituciones y personas interesados en nuevas demandas sociales.

Me gustaría acabar con este fragmento de Alicia en el país de las maravillas:

"- Alicia: Señor Gato, ¿puede indicarme por qué camino debo ir?

- Gato: Depende de adónde quiera usted llegar.

- Alicia: ¡Ah!, eso no importa, a condición de llegar muy, muy lejos...

- Gato: Pues entonces no importa el camino, puede usted estar segura de conseguirlo, a condición de que camine mucho, mucho tiempo..."

$Y$ es que cabe responder con eficacia a los constantes cambios que está experimentando la sociedad, adaptándose y respondiendo con habilidad, seriedad y convenientemente a los mismos.

\section{BIBLIOGRAFÍA}

- ASSmANN, H. (2002) Placer y ternura en la educación. Hacia una sociedad aprendiente. Madrid: Ed. Narcea, 2002

- BATESON, G. (2013) El proceso de la creatividad bajo el enfoque sistémico en la organización aprendiente [en línea] $<$ http://es.scribd.com/doc/174260353/Gregory-Bateson-ElProceso-de-La-Creatividad-Bajo-El-Enfoque-Sistemico> [Consulta: 10/10/2013]

- BAUTISTA, G.; BORGES, F.; FORÉS, A. (2008) Didáctica universitaria en Entornos Virtuales de Enseñanza-Aprendizaje. Madrid: Ed. Narcea, 2008

- GUARRERA, A. (2001) Análisis para un aprendizaje integrado. Reflexión académica en diseño y comunicación, 2 , Buenos Aires, 2001, pp. 37-38

- HAUg, G. (2013) Hacia más diversidad universitaria. Madrid: Fundación Europea Sociedad y Educación [en línea] <http://issuu.com/efse/docs/00._cuaderno_de_trabajo_6> [Consulta: 11/10/2013] 